\title{
AN ENGINEERING APPROACH FOR HARVESTING ENERGY FROM WIND, WAVE AND STORM
}

\author{
Viet Nguyen
}

No 19, Alley 479/53, Linh Nam Ward, Hoang Mai District, Hanoi, Vietnam

\begin{abstract}
The world is now facing energy scarcity and climate change. In that context, renewable energy is gradually replacing fossil fuels. However, this source of energy has not been fully exploited. Some natural disasters bring a lot of energy but are not exploited; in particular, storms are among the heavyweights. In this paper, I propose a device for harvesting energy from wind, waves and especially storms. One such device is called a Stormbuoy. If used in practice and deployed on a large scale, the Stormbuoy will harvest significant amounts of energy from wind, waves and storms. This not only solved the problem of energy scarcity but also mitigated the destruction of the storm with humans.
\end{abstract}

\section{KEYWORDS}

Harvesting energy, wind, wave, storm, Venturi effect, hydrogen, electrolysis

\section{INTRODUCTION}

The Stormbuoy is a device that harvests energy from wind, waves and especially storms. On normal days (days without storm), this buoy is fixed offshore. Above the water, the windtrap harvests wind in all directions. After entering the wind trap, the wind velocity is increased before impacting the turbine. In this way, a Stormbuoy can work in low wind conditions. Below the water, the motion of Stormbuoy caused by waves is used to generate electricity [1]. Finally, the electricity produced by the wind turbine and the motion of the buoy will be provided to the grid.

On stormy days, Stormbuoys are removed from the fixed position and moved to the location of a storm. Here, they float freely on the sea although they are still held by the anchor. Storm wind from outside enters the wind trap in all directions. By a different path, the storm wind velocity is decreased before impacting the turbine. In this way, the turbine can work efficiently and avoid damage in violent conditions of the storm $[2,3]$. The electricity generated by the turbine is used for electrolysis of seawater to produce hydrogen [4]. This amount of hydrogen is then stored in a closed cavity inside the buoy body and eventually will be pumped into the hydrogen storage tank on land.

In summary, the Stormbuoy will harvest energy from the storm by changing the wind speed of the storm based on the Venturi effect [5]. Traditionally, it is difficult to harvest wind energy from storms because of violent winds that will cause wind turbines to fail [3, 4]. However, inside the Stormbuoy, the wind speed of a storm (hundreds of kilometers per hour) will be reduced to the normal wind speed (about 30 to 40 kilometers per hour) so that turbines can work efficiently without damaged. As a result, harvesting energy from a storm would be like harvesting energy

DOI: $10.5121 /$ aeij.2019.6101 
Advanced Energy: An International Journal (AEIJ), Vol. 6, No. 1, January 2019

from a normal wind.Stormbuoys transform wind energy of storms into useful energy. Thus, they significantly reduce the destructive power of storms [6].

\section{Modeling}

A Stormbuoy (Figure1) consists of five components: wind trap, turbine, generator, water cavity and hydrogen cavity.

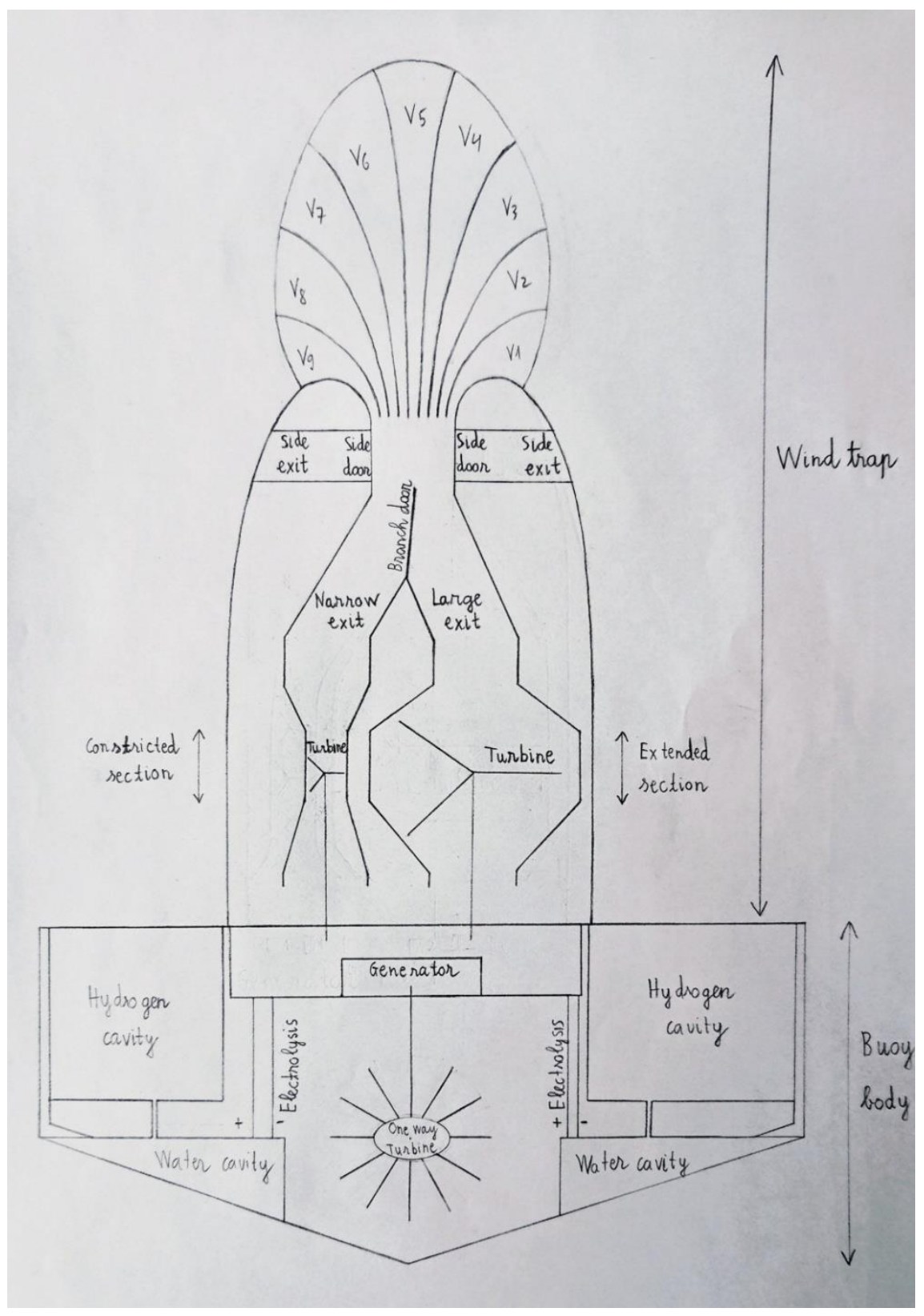

Figure 1: The model of a Stormbuoy 


\subsection{Wind TRAP}

This is the most important part of a Stormbuoy. The mission is to concentrate wind from all directions towards the turbine and control the velocity of wind. A wind trap consists of multiple entrances (named $\mathrm{V}_{1}$ to $\mathrm{V}_{9}$ ) while only two exits (narrow exit and large exit). The wind trap is designed so that the wind velocity can increase or decrease based on the Venturi effect [7]. This is decided by a mobile door, called a branch door, located inside the wind trap. This door divides the exit of wind trap into two parts: narrow exit and large exit. Inside the narrow exit, the wind velocity is increased at a constricted section before impacting the turbine. Inside the large exit, the wind velocity is decreased at an extended section before impacting the turbine (In order for the wind velocity to decrease based on the Venturi effect [5], in fact, the size of an extended section must be much larger than the total size of all entrances. Therefore, large exit in Figure 1 is for reference only). As a result, a Stormbuoy can work at a variety of wind velocities, from low wind to storm wind. The narrow exit will harvest wind on normal days and the large exit will harvest violent wind from storms. These two exits are called two main exits. In addition, a wind trap of Stormbuoy has two side exits (mentioned in "Working Principle").

Two main exits of a wind trap can be designed in two cases: horizontal or vertical. In this paper, I designed them vertically.

\subsection{TURBINE}

In a Stormbuoy, the turbine is installed in three locations: In the narrow exit, the wind turbine is installed at a constricted section to harvest wind energy on normal days; in the large exit, the wind turbine is installed at an extended section to harvest wind energy from storms; in the buoy body, the one-way turbine (The turbine can only move in one certain direction because blades are not firmly attached to the shaft. As a result, regardless of the buoy moving up or down, the turbine will only turn in one direction) is installed to convert the up and down motion of Stormbuoy caused by waves into the rotation of turbine to generate electricity [1].

\subsection{GENERATOR}

Generator is attached to turbines to generate electricity from the turbine's rotational motion $[7,8]$.

\subsection{WATER CAVITY}

On stormy days, water cavity is opened to allow seawater enters. Then electricity from generator will be used for electrolysis of seawater to produce hydrogen [4].

\subsection{HYDROGEN CAVITY}

Hydrogen produced from the electrolysis will be stored in the hydrogen cavity in the form of compressed air [9]. At the original state, the interior of this cavity is a vacuum.

\section{Working Principle}

The Stormbuoy is designed to work in two cases: On normal days, means that days without storm (Figure2) and on stormy days (Figure3). 


\subsection{HARVESTING WIND ENERGY AND WAVE ENERGY ON NORMAL DAYS}

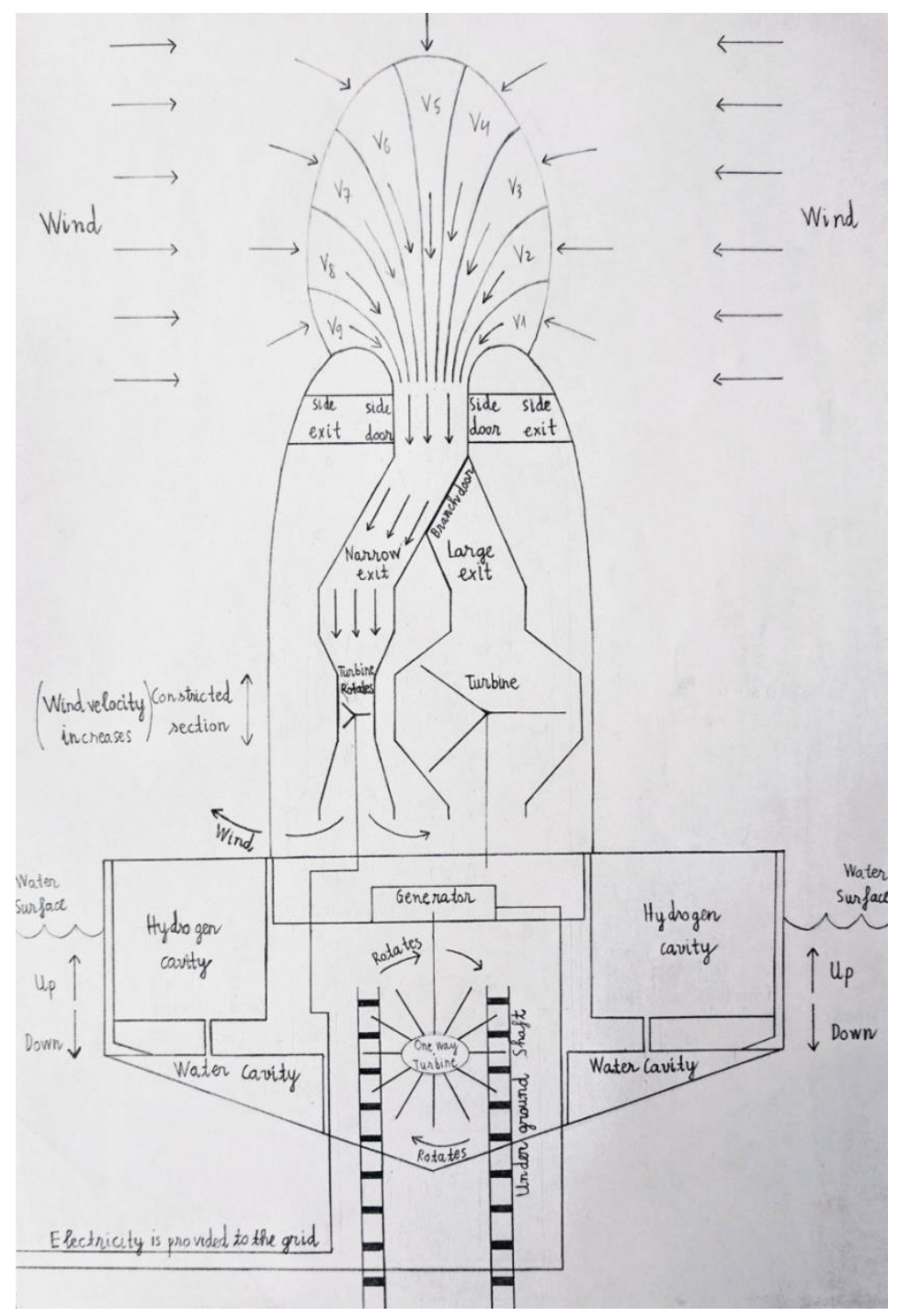

Figure 2: Working principle of a Stormbuoy on normal days

On normal days, the Stormbuoy is fixed offshore. Above the water, entrances of the wind trap spread 360 degrees to harvest wind. The wind outside in all directions follows these entrances to get into the wind trap. Inside the wind trap, the branch door closes the large exit and simultaneously opens the narrow exit. As a result, the wind enters the narrow exit. At a constricted section, the wind velocity increases based on the Venturi effect [5]. The wind energy causes the turbine rotates to generate electricity $[10,11]$. At the end of the journey, the wind escapes from the narrow exit and goes outside. Electricity will be provided to the grid via an underground cable system.

Below the water, the buoy body is attached to a fixed underground shaft. Accordingly, waves impact on the buoy and cause it to move up and down [12]. Inside the buoy body, a one-way 
turbine is combined with this underground shaft. Whenever the Stormbuoy moves up or down, an underground shaft impacts on the turbine's blades and rotates it. The rotation of a one-way turbine is used to generate electricity [7, 8]. Similarly, the electricity generated by the motion of Stormbuoy will be provided to the grid via an underground cable system.

\subsection{HARVESTING WIND ENERGY FROM STORMS}

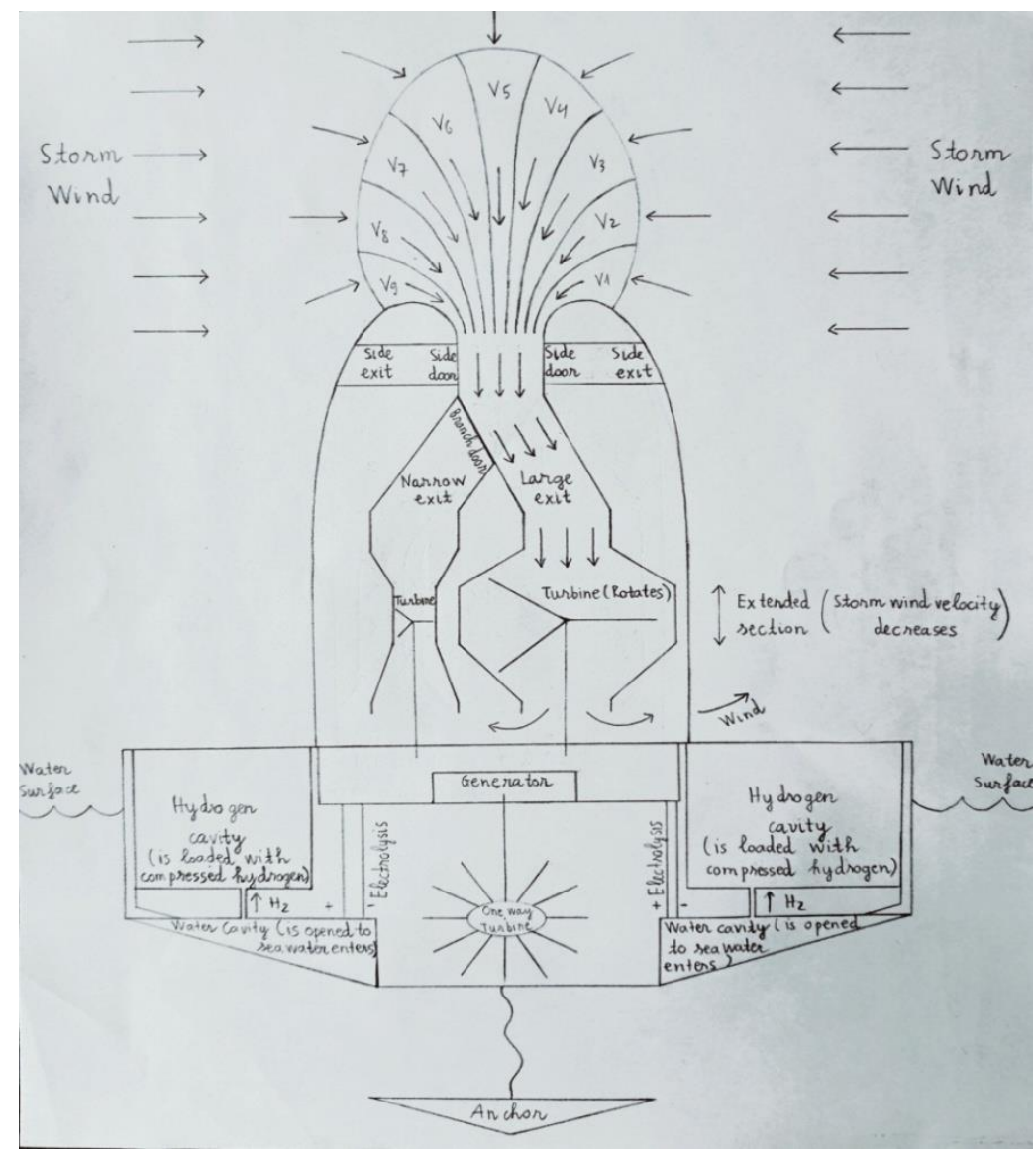

Figure 3: Working principle of a Stormbuoy on stormy days

On stormy days, Stormbuoys are removed from the fixed position and connected by hooks. Combined with the storm tracking map [4], Stormbuoys are transported by a ship to locations where the storm will pass. When it comes to the right place, the ship will drop Stormbuoys. Next, Stormbuoys will anchor to keep them, not letting them drift too far away from the suitable location.

When the storm arrives, storm wind in all directions is sucked into the wind trap through multiple entrances. Inside the wind trap, the branch door closes the narrow exit and simultaneously opens the large exit. As a result, storm wind enters the large exit. At an extended section, the storm wind velocity decreases based on the Venturi effect [5], which will help the turbine to avoid damage if storm wind is very violent $[2,3]$. Here, the wind energy causes the turbine rotates to generate electricity $[10,11]$. At the end of the journey, storm wind escapes from the large exit and goes outside. Below the water, the water cavity is opened to allow seawater enters. Next, the 
electricity generated is used for electrolysis of seawater. The end result is that hydrogen is produced, compressed and then loaded into the hydrogen cavity for storage $[4,9]$.

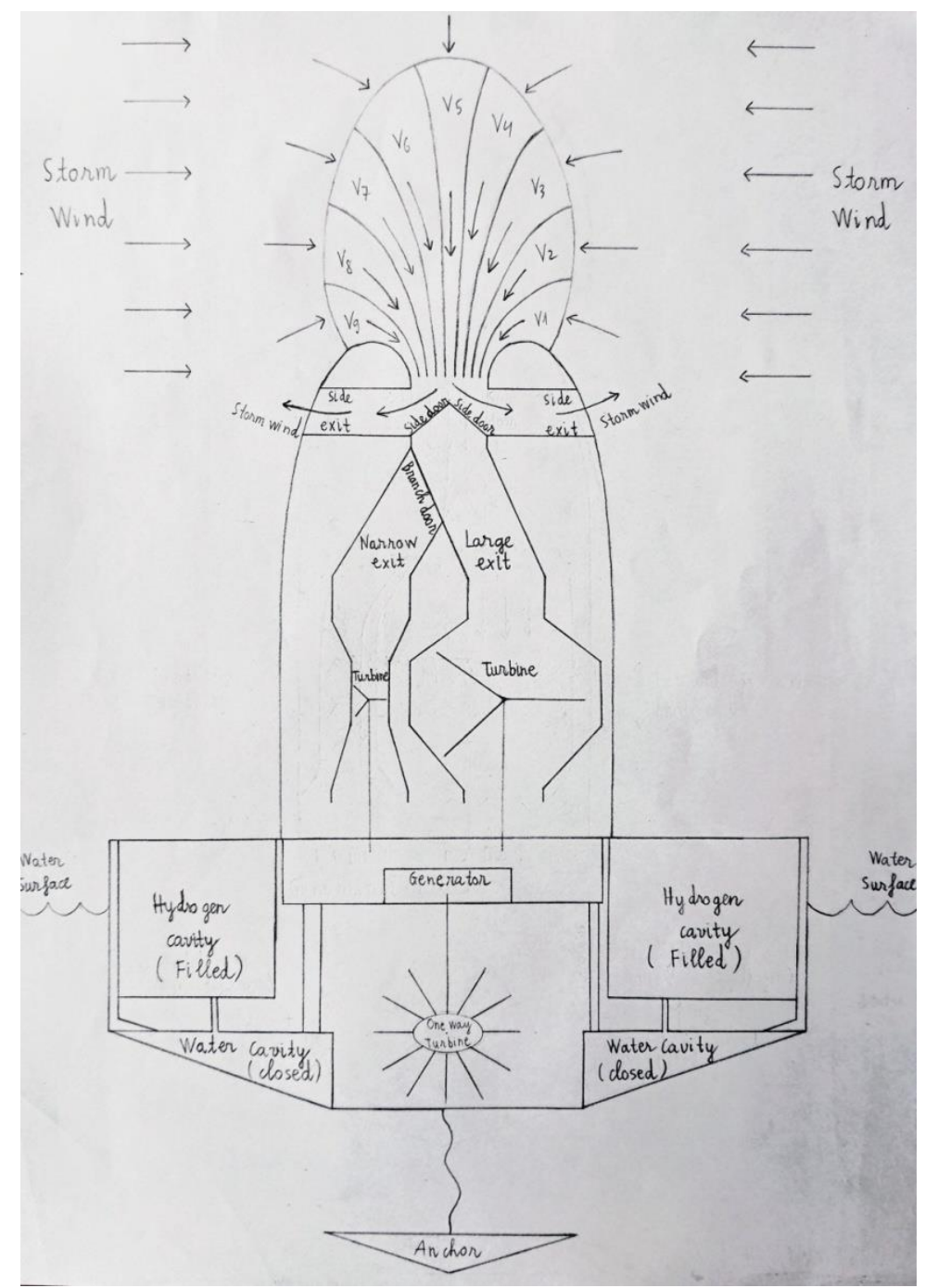

Figure 4: Working principle of a Stormbuoy when full of energy

When the Stormbuoy is full of energy, means that hydrogen in the hydrogen cavity is filled, two side doors that located above a branch door will close two main exits and simultaneously open two side exits (Figure4). Accordingly, storm wind will escape from the wind trap through two side exits and no impact on the turbine, thus avoiding unnecessary damage to the turbine [15]. After the storm passes, Stormbuoys will be transported to the shore for pumping into land-based hydrogen storage tanks, and eventually, they will be fixed offshore at original locations. 


\section{RESULTS}

\subsection{HARVESTING MANY FORMS OF ENERGY}

The combination of various components allows the Stormbuoy can harvest many forms of energy, from wind and wave energy on normal days to storm wind energy on stormy days.

\subsection{WORKING AT A VARIETY OF WIND VELOCITIES}

Based on the Venturi effect [5], the wind velocity will increase or decrease. This allows the Stormbuoy can control the velocity of wind. The result is the Stormbuoy can work at a variety of wind velocities, from low wind to storm wind.

\subsection{HARVESTING WIND ENERGY OPTIMALLY}

Entrances of the wind trap spread 360 degrees; as a result, wind in all directions is sucked into the wind trap.

\subsection{Protecting THE TURBINE FROM DAMAGE}

Two side exits of wind trap allow the wind to go out. As a result, the turbine will avoid violent winds of the storm at times when energy is not needed.

\section{DisCUSSION}

Unlike passive structures fixed on land, Stormbuoys are floating devices on the sea, so they will be less damaged when impacted. When storm wind hits, it will oscillate continuously and then return to equilibrium. As a result, the Stormbuoy will be completely stable with the destruction from the storm. The Stormbuoy is like a Roly-poly toy that cannot fall down when touched [16]. Stormbuoys harvest wind energy from storms and transform into useful energy. Thus, they significantly reduce the destructive power of storms. This is similar to offshore wind farms in Stanford's study [6].

\section{REFERENCES}

[1] http://www.alternative-energy-tutorials.com/wave-energy/wave-energy.html

[2] https://www.newscientist.com/article/dn23848-why-storm-winds-turned-wind-turbine-into-a-fireball/

[3] https://windsecure.myshopify.com/blogs/news/80446147-a-violent-wind-destroyed-a-wind-turbine

[4] https://doi.org/10.1002/adma.201707261

[5] "The Venturi effect". Wolfram Demonstrations Project. Retrieved 2009-11-03.

[6] https://news.stanford.edu/news/2014/february/hurricane-winds-turbine-022614.html

[7] https://www.turbinegenerator.org/generator-works/

[8] https://www.e-education.psu.edu/egee401/content/p6_p2.html

[9] Compressed Hydrogen Storage. Retrieved from http://www.fsec.ucf.edu/en/consumer/hydrogen/basics/documents/task2_gaseous_h2.pdf 
[10] https://www.explainthatstuff.com/windturbines.html

[11] https://www.mpoweruk.com/wind_power.htm

[12] https://tethys.pnnl.gov/technology-type/wave

[13] https://www.windy.com

[14] http://edition.cnn.com/interactive/storm-tracker/

[15] http://www.ediweekly.com/overheated-bearings-gearboxes-among-causes-wind-turbine-fires/

[16] https://doi.org/10.1088/0143-0807/37/6/062001

\section{AUTHOR}

\section{VIET NGUYEN}

Tran Phu electric mechanical joint stock company, 41 Phuong Liet St., Hanoi, Vietnam 